AB0889 SARCOPENIA AND HIP FRACTURE IN GERIATRIC POPULATION

K. Boskovic ${ }^{1}$, S. Pantelinac ${ }^{1}$, S. Tomasevic-Todorovic ${ }^{1}$, T. Spasojevic ${ }^{1}$, D. SimicPanic ${ }^{1}$, N. Boskovic ${ }^{2} .{ }^{1}$ University of Novi Sad, Medical rehabilitation Clinic, Novi Sad, Serbia; ${ }^{2}$ Masaryk University, Brno, Czech Republic

Background: Sarcopenia is a loss of skeletal muscle mass, muscle strength, and function, with an impact on the quality of life, increased risk of bone loss and fracture, which is associated with normal aging.

Objectives: To determine the effect of sarcopenia on the recovery of patients after hip fracture, their fitness, functionality, and quality of life

Methods: A prospective study had 60 patients with hip fractures of both sexes, $>65$ years of age (70.8), in the experimental group of patients with sarcopenia and the control group without sarcopenia. All anthropometric measurements were performed: $\mathrm{BMI}(\mathrm{kg} / \mathrm{m} 2)$, waist circumference, the volume of the upper arm and lower leg muscle mass, handgrip force $(\mathrm{kg})$ - dynamometry. The following questionnaires were used to assess functionality, mobility, and quality of life: Health assessment questionnaire (HAQ), Harrison hip score (HHS), Sarcopenia and Quality of life (SarQol)

Results: Muscle mass (BMI) was significantly lower in the experimental group patients $(p<0.005)$ compared to the control group. The clamp strength measured by the dynamometer was significantly lower in patients with hip fractures ( $p$ $<0.005$ ) compared to the control group. About $2 / 3$ of the subjects with sarcopenia and hip fracture have a severe and complete physical disability. There was a significant difference in all domains of quality of life between subjects with hip fractures and the control group due to the presence of sarcopenia $(p<0.005)$.

Conclusion: The presence of sarcopenia indicates consequently reduced functionality and a degree of disability in patients with hip fractures, slows recovery and increases the need for mobility aids, thus extending hospital stay and patient recovery. References:

[1] He H, Liu Y, Tian Q, Papasian CJ, Hu T, Deng HW. Relationship of sarcopenia and body composition with osteoporosis. Osteoporos Int. 2016 Feb; 27(2):473-82. https://doi.org/10.1007/s00198-015-3241-8 PMID: 26243357

[2] Oliveira A, Vaz C. The role of sarcopenia in the risk of osteoporotic hip fracture. Clin Rheumatol. 2015 Oct; 34(10):1673-80. https://doi.org/10.1007/ s10067-015-2943-9 PMID: 25912213

[3] Tarantino U, Piccirilli E, Fantini M, Baldi J, Gasbarra E, Bei R. Sarcopenia and fragility fractures: molecular and clinical evidence of the bone-muscle interaction. J Bone Joint Surg Am. 2015 Mar 4; 97(5):429-37. https://doi. org/10.2106/JBJS.N.00648 PMID: 25740034 Benichou O, Lord SR. Rationale for Strengthening Muscle to Prevent Falls and Fractures: A Review of the Evidence. Calcif Tissue Int. 2016 Jun; 98(6):531-45. https://doi.org/10.1007/ s00223-016-0107-9 PMID: 26847435

[4] Hirschfeld HP, Kinsella R, Duque G. Osteosarcopenia: where bone, muscle, and fat collide. Osteoporos Int. 2017 Oct; 28(10):2781-2790. https://doi. org/10.1007/s00198-017-4151-8 PMID: 28733716

[5] Rantanen T, Volpato S, Ferrucci L, Heikkinen E, Fried LP, Guralnik JM. Handgrip strength and causespecific and total mortality in older disabled women: exploring the mechanism. J Am Geriatr Soc. 2003 May; 51(5):636-41. https://doi.org/10.1034/j.1600-0579.2003.00207.x PMID: 12752838

[6] Syddall H, Cooper C, Martin F, Briggs R, Aihie Sayer A. Is grip strength a useful single marker of frailty? Age Ageing. 2003 Nov; 32(6):650-6. https:// doi.org/10.1093/ageing/afg111 PMID: 14600007

[7] Chen LK, Liu LK, Woo J, Assantachai P, Auyeung TW, Bahyah KS, et al. Sarcopenia in Asia: consensus report of the Asian Working Group for Sarcopenia. J Am Med Dir Assoc. 2014 Feb; 15(2):95-101. https://doi.org/10.1016/j. jamda.2013.11.025 PMID: 24461239

[8] Wehren LE, Hawkes WG, Hebel JR, Orwig DL, Magaziner J. Bone mineral density, soft tissue body composition, strength, and functioning after hip fracture. J Gerontol A Biol Sci Med Sci. 2005 Jan; 60 (1):80-4. https://doi. org/10.1093/gerona/60.1.80 PMID: 15741287

Disclosure of Interests: None declared

DOI: 10.1136/annrheumdis-2020-eular.5440

\section{AB0890 VITAMIN D PROMOTES BONE MINERAL DENSITY ACCRUAL AFTER DISCONTINUATION OF ALENDRONATE.}

A. Catalano ${ }^{1}$, F. Bellone ${ }^{1}$, A. Gaudio ${ }^{2}$, M. C. Sottile ${ }^{1}$, S. A. Stoian ${ }^{1}$, F. Lo Piano ${ }^{1}$, S. Maisano ${ }^{1}$, F. Corica ${ }^{1}$, N. Morabito ${ }^{1} .{ }^{1}$ University of Messina, Department of Clinical and Experimental Medicine, Messina, Italy; ${ }^{2}$ University of Catania, Department of Clinical and Experimental Medicine, Catania, Italy

Background: Vitamin D repletion is known to maximize the response to bisphosphonates (BPs) in terms of both bone mineral density (BMD) changes and anti-fracture efficacy. The contribute of vitamin to BMD after discontinuation of BPs has been poorly investigated.
Objectives: To explore whether change of vitamin $D$ status may contribute to the tail effect of alendronate (ALE) on BMD.

Methods: Participants in this retrospective study were postmenopausal osteoporotic women exposed to ALE. Either cholecalciferol or calcifediol have been administered, as vitamin D supplementation in accordance to good clinical practice, during ALE treatment and after ALE discontinuation. BMD was evaluated by Dual-energy X-ray absorptiometry (DXA) at lumbar spine and femoral site. Vitamin D status has been checked by measuring 25(OH)D serum levels through HPLC. Surrogate bone formation and resorption markers (i.e. C-terminal telopeptide of type I collagen (CTX) and alkaline phosphatase (ALP), respectively) were also evaluated. The Fracture Risk Assessment Tool (FRAX) served to estimate the participants' 10-year fracture risk for major osteoporotic and hip fracture.

Results: 88 postmenopausal osteoporotic women (age $61.14 \pm 6.96 \mathrm{yr}$.) were included in the final analysis. The 10-year probability of major and hip fractures was $18.31 \pm 11.51$ and $8.60 \pm 10.55 \%$, respectively. Participants were exposed to ALE treatment for $31.27 \pm 20.69$ months; then they stopped treatment for 33.33 \pm 18.97 months. Change of BMD was inversely related to drug holiday $(r=-0.27$, $\mathrm{p}=0.005)$. Modification of $25(\mathrm{OH}) \mathrm{D}$ was inversely associated with change of ALP $(r=-0.22, p=0.018)$ and CTX levels $(r=-0.3, p=0.06)$. By distributing participants in tertiles according to variation of $25(\mathrm{OH}) \mathrm{D}$ levels over time, women allocated in the tertile with the higher increase of $25(\mathrm{OH}) \mathrm{D}$ showed a 5.7\% BMD gain that was two times larger in comparison with participants with lower increase of 25(OH)D. At a multiple regression analysis, after correcting for ALE treatment duration, bone turnover marker modifications, BMI and age at menopause, BMD change at lumbar spine was significantly associated with time since menopause $(B=2.28$, SE 0.44 $p<0.0001$ ), FRAX score ( $\beta=-0.65$, SE $0.29, p=0.03$ ), drug holiday duration $(B=-2.17$ SE 0.27, $p<0.0001$ ) and change of $25(\mathrm{OH}) \mathrm{D}$ levels ( $\beta=0.15$ SE $0.03, p=0.0007$ ).

Conclusion: After ALE discontinuation, modification of BMD are strictly associated with change of vitamin D status.

Disclosure of Interests: None declared

DOI: 10.1136/annrheumdis-2020-eular.4627

\section{AB0891 BARE TO THE BONE - AN AUDIT OF RENAL BONE DISEASE AGAINST KDIGO GUIDELINES}

N. Cernovschi ${ }^{1}$, S. Zeb ${ }^{1}$, T. Salter ${ }^{1}$, M. Lloyd ${ }^{1} .{ }^{1}$ Frimley Park Hospital, Frimley, United Kingdom

Background: Chronic kidney disease-mineral and bone disorder (CKD-MBD) is complex and management can be difficult. We aimed to compare management of our CKD patients to $2018 \mathrm{KDIGO}$ guidelines. The guidelines suggest checking calcium and phosphate (Ca/PO4) within 12 mths in CKD 3a and 3b, within 6 mths for CKD 4, and within 3 mths for CKD 5. Parathyroid hormone (PTH) should be checked at baseline in CKD 3a-b, within 12 mths in CKD 4 and within 6mths in CKD 5. Alkaline phosphatase (ALP) should be measured within 12 mth in CKD 4 and 5. 25- $(\mathrm{OH}) \mathrm{D}$ levels 'might' be measured at baseline in CKD 3a to 5D. BMD scanning is suggested if the result will impact treatment decisions. Lateral abdominal $X$ ray is recommended as an alternative to $C T$ for detection of vascular calcification. Calcitriol and vitamin $D$ analogues are no longer routinely advised in CKD 3a-5; 25- $(\mathrm{OH}) \mathrm{D}$ insufficiency should be corrected as in the normal population

Objectives: To compare management of our CKD patients to 2018 KDIGO guidelines

Methods: We randomly selected 70 patients in whom data was available from renal clinics between May and September 2019.

Results: Mean age was 67.3 yrs. 41 male, 29 female. 33 patients had CKD 3a-b; 31 had CKD 4; 6 had CKD 5. Mean duration of CKD was 10.6 yrs. 10 patients were taking activated vitamin $\mathrm{D}$ analogues; 13 were taking $25-(\mathrm{OH}) \mathrm{D}$ analogues. $25-(\mathrm{OH}) \mathrm{D}$ levels ranged from $24-158 \mathrm{nmol} / \mathrm{L}$ (mean $65 \mathrm{nmol} / \mathrm{L}$ ). PTH levels ranged from 2- 69pmol/L (mean 23pmol/L). 3 patients were taking bisphosphonates. 44 had previous lumbar spinal imaging; vertebral fractures were evident in $4(9 \%) .12$ patients had had DXA scans; lowest T score was -2.5 . Table 1 - tests within suggested time frames:

\begin{tabular}{lccc}
\hline & CKD 3a-3b & CKD 4 & CKD 5 \\
\hline Ca/ PO4 & $33(100 \%)$ & $29(93 \%)$ & $6(100 \%)$ \\
ALP & $33(100 \%)$ & $31(100 \%)$ & $6(100 \%)$ \\
PTH & $14(42 \%)($ ever $)$ & $8(26 \%)$ & $3(50 \%)$ \\
25-(OH)D & $8(24 \%)($ ever $)$ & $8(26 \%)($ ever $)$ & $1(14 \%)($ ever $)$ \\
\hline
\end{tabular}

Conclusion: Optimum PTH levels in CKD patients are not known, and therapeutic options in CKD-MBD often limited. Nevertheless, our results suggest that bone biochemistry could be checked more consistently in CKD patients. Although detection of vascular calcification may not alter renal management, abdomina imaging provides an opportunity to screen for vertebral fracture, present in a 
significant number of our patients. The KDIGO guidelines offer a framework to work with our renal colleagues, as many patients will be jointly managed.

References:

[1] Diagnosis, Evaluation, Prevention, and Treatment of Chronic Kidney

[2] Disease-Mineral and Bone Disorder: Synopsis of the Kidney Disease:

[3] Improving Global Outcomes 2017 Clinical Practice Guideline Update. Ann Int Med 2018

Disclosure of Interests: NATALIA CERNOVSCHI: None declared, SHABEENA ZEB: None declared, TRACEY SALTER: None declared, MARK LLOYD Speakers bureau: $£ 700$ into department fund

DOI: 10.1136/annrheumdis-2020-eular.1490

\section{AB0892 1 PREGNANCY AND LACTATION ASSOCIATED OSTEOPOROSIS: FIRST CASE SERIES IN IRAN}

M. Aghaei ${ }^{1}$, S. Sedighi ${ }^{1}$, M. Hassani ${ }^{1}$, M. R. Damirchi ${ }^{1}{ }^{1}$ Golestan University of Medical Sciences, Golestan Rheumatology Research Center, Gorgan, Iran (Islamic Republic of)

Background: Osteoporosis is a common rheumatologic disorder in postmenopausal women which could lead to morbidities later in life. However, this condition has not been properly studied in premonapausal women.

During pregnancy, the fetus needs a total of 30 grams of calcium for its skeleton and during lactation, $200 \mathrm{mg}$ of calcium is secreted in the breast milk per day which the mother acquires by doubling its intestinal absorption rate. If the calcium intake of the mother is not sufficient to satisfy the fetus' needs, it will be provided by bone resorption, which will decrease the maternal calcium reserves [1].

Pregnancy and Lactation Associated Osteoporosis (PLAO) is a rare condition associated with pregnancy that should be considered in premenopausal women. The most commonly affected sites are the vertebrae and, more rarely, the hips, pubic rami and ribs [2].

An important complication of osteoporosis is fracture and a preemptive diagnosis and treatment thereof, can have drastic effects on the quality of life.

Objectives: Our objective is to document the relevant risk factors, present signs and symptoms, course of illness, and response to treatment in three cases of $\mathrm{PLAO}$. It is quite possible that osteoporosis in pregnancy

and lactation is more frequent than recognized, simply because it is only recognized when an-unexpected fracture occurs[3]. Thus, in this article we are presenting three cases that showcase the need for more rigorous research on PLAO risk factors, the need for screening in high risk patients, and the advantages of early detection in patients' outcome.

Methods: The clinical cases of the patients whose PLAO diagnoses had been confirmed by both a radiologist and a rheumatologist in the past year was extracted. Information related to demographic indices, clinical manifestations, and the treatment methods was evaluated and compared.

Results: In the past year, three patients with a chief complaint of low-back pain have visited our clinic. The first, a 22-year-old woman with a nursing history of 2 months, the next one, a 31-year-old woman with a nursing history of 3 months, and the last, a 22-year-old woman with a nursing history of 4 months. All three patients had low back pain and tenderness. Two out of three patients had deficient vitamin $\mathrm{D}$ levels and the other had a normal one. All three patients had low BMD in lumbar vertebra and MRI imagings indicative of osteoporotic fracture.

Table 1. General and pregnancy-relatedcharacteristics of the case studies

\begin{tabular}{lccc}
\hline Variables & Case 1 & Case 2 & Case 3 \\
\hline Age & 22 & 31 & 22 \\
Nursing duration & 2 months & 3 months & 4 months \\
BMD(lumbar spine) & -3.6 & -3.5 & -3.1 \\
Vitamin D level & $12.6(\mathrm{ng} / \mathrm{ml})$ & $31.6(\mathrm{ng} / \mathrm{ml})$ & $8(\mathrm{ng} / \mathrm{ml})$ \\
Fracture & $\mathrm{T}_{12,} \mathrm{~L}_{1}$ & $\mathrm{~T}_{4,5,6,7,10}, \mathrm{~L}_{2}$ & $\mathrm{~L}_{1,2,3,4,5}$ \\
\hline
\end{tabular}

Conclusion: Since the symptoms of PLAO are often confused with pain in other low-back pain conditions associated with pregnancy, PLAO is a mostly overlooked diagnosis[4]. It is only recognized when an unexpected fracture occurs [3]Therefore, high risk patients with less severe symptoms are usually not diagnosed and thusly, should undergo a proper screening test, so that they are recognized early and the morbid sequelae are averted.

References:

[1] Kovacs, C. S., and S. H. Ralston. "Presentation and Management of Osteoporosis Presenting in Association with Pregnancy or Lactation." Osteoporosis International, vol. 26, no. 9, 2015, pp. 2223-2241., doi:10.1007/ s00198-015-3149-3.
[2] Gregorio, Silvana Di, et al. "Osteoporosis with Vertebral Fractures Associated with Pregnancy and Lactation." Nutrition, vol. 16, no. 11-12, 2000, pp. 1052-1055., doi:10.1016/s0899-9007(00)00430-5.

[3] Bartl, Reiner, and Christoph Bartl. "The Osteoporosis Manual." 2019, doi:10.1007/978-3-030-00731-7.

[4] Eroglu, Semra, et al. "Evaluation of Bone Mineral Density and Its Associated Factors in Postpartum Women." Taiwanese Journal of Obstetrics and Gynecology, vol. 58, no. 6, 2019, pp. 801-804., doi:10.1016/j.tjog.2019.09.013.

Disclosure of Interests: None declared

DOI: 10.1136/annrheumdis-2020-eular.2665

\begin{tabular}{|l|l|}
\hline AB0893 & THE EFFECTS OF THREE DIFFERENT VITAMIN D3 \\
SUPPLEMENTATION REGIMENS IN DEFICIENT \\
SUBJECTS - A RANDOMIZED OPEN-LABEL \\
PARALLEL GROUP STUDY.
\end{tabular}

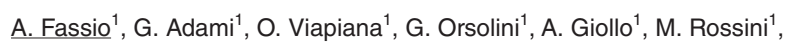
D. Gatti ${ }^{1}{ }^{1}$ Rheumatology Unit, University of Verona, Verona, Italy

Background: Currently, most experts agree that levels of serum $25 \mathrm{OH}$-Vitamin $\mathrm{D}(25 \mathrm{OHD})$ lower than $20 \mathrm{ng} / \mathrm{mL}$ represent an acceptable threshold for deficiency (1). However, recommendations for vitamin D supplementation vary between scientific societies, and the best regimen to treat deficient patients is still not clear (1)

Objectives: The aim of our study was to compare the pharmacokinetic profile of three different regimes of cholecalciferol supplementation in terms of $250 \mathrm{HD}$ exposure and their safety profiles.

Methods: We evaluated, in healthy subjects affected by vitamin $\mathrm{D}$ deficiency (defined as $250 \mathrm{HD}<20 \mathrm{ng} / \mathrm{mL}$ ), 18 to 60 years of age, the efficacy of three different oral supplementation regimens: daily 10,000lu administered for 8 weeks, weekly 50,000 lu for 12 weeks and biweekly 100,000lu for 12 weeks. Serum 25OHD was dosed at baseline, at week 2, 4, 8 in all three groups and also at week 12 in the 50,000 and 100,000lu groups (the blood sample was taken before the drug administration if scheduled on the same day). Baseline characteristics and $250 \mathrm{HD}$ changes from baseline to the various observation points were tested with ANOVA and t-test. 25OHD was measured by the IDS-ISYSMulti-Discipline automated analyser (Immunodiagnostic System, Boldon, UK) based on chemiluminescence technology. The CV intra-assay measured in our laboratory was 6\% (inter-assay CV $9 \%$ ). The study was authorized by the local ethical committee (protocol DIBA/11. Supported by Abiogen Pharma, Italy).

Results: A total of 75 subjects were randomized to receive one supplementation regimen. The descriptive of the sample at baseline and relative $250 \mathrm{HD}$ levels at the various observation points are reported in table 1. 25OHD increased significantly already at week 2 in all three groups $(p=0.000)$. At week $2,100 \%$ of the subject of the daily regimen group presented $25 \mathrm{OHD}$ levels $>20 \mathrm{ng} / \mathrm{mL}, 96 \%$ in the weekly and $88 \%$ in the biweekly ones.

Table 1. mean values $\pm S D$ at the different observation points.

\begin{tabular}{|c|c|c|c|c|}
\hline Parameter & $\begin{array}{l}\text { Daily } 10.000 \mathrm{Ui} \\
\qquad(\mathrm{N}=25)\end{array}$ & $\begin{array}{c}\text { Weekly } 50.000 \\
\text { Ui } \\
(n=25)\end{array}$ & $\begin{array}{c}\text { Biweekly } \\
100.000 \mathrm{Ui} \\
(\mathrm{N}=25)\end{array}$ & p-value \\
\hline M:F & $12: 13$ & $7: 18$ & $12: 13$ & \\
\hline Age (years) & $30.2 \pm 9.9$ & $36.7 \pm 8.7$ & $35.4 \pm 11.0$ & ${ }^{*} 0.059$ \\
\hline Body Weight (kg) & $65.8 \pm 13.2$ & $67.8 \pm 10.8$ & $66.6 \pm 13.7$ & *NS \\
\hline Height $(\mathrm{m})$ & $1.7 \pm 0.1$ & $1.68 \pm 0.1$ & $1.7 \pm 0.1$ & ${ }^{*} \mathrm{NS}$ \\
\hline BMI & $22.55 \pm 2.7$ & $23.8 \pm 2.2$ & $22.8 \pm 2.7$ & ${ }^{*} \mathrm{NS}$ \\
\hline $\begin{array}{l}\text { Baseline 250HD (ng/ } \\
\mathrm{mL} \text { ) }\end{array}$ & $14.6 \pm 3.9$ & $12.8 \pm 3$ & $13.5 \pm 4.1$ & ${ }^{*} \mathrm{NS}$ \\
\hline 25OHD week 2 & $32.3 \pm 5$ & $26.5 \pm 3.4$ & $25.6 \pm 5$ & ${ }^{\mathrm{a}} 0.007^{\mathrm{b}} 0.000$ \\
\hline 250HD week 4 & $55 \pm 10.1$ & $39.9 \pm 4.2$ & $36.9 \pm 7.2$ & ${ }^{\mathrm{a}} 0.000^{\mathrm{b}} 0.000$ \\
\hline 25OHD week 8 & $79.1 \pm 16.2$ & $53.5 \pm 7.2$ & $46.4 \pm 8.2$ & $\begin{array}{l}{ }^{\mathrm{a}} 0.000^{\mathrm{b}} 0.000 \\
{ }^{\mathrm{c}} 0.001\end{array}$ \\
\hline 25OHD week 12 & NA & $58.5 \pm 7.8$ & $50.6 \pm 9.6$ & ${ }^{b} 0.000^{c} 0.001$ \\
\hline
\end{tabular}

${ }^{*}$ ANOVA test.

aDaily 10.000 Ui vs weekly $50.000 \mathrm{Ui}$

${ }^{b}$ Daily 10.000 Ui vs Biweekly $100.000 \mathrm{Ui}$

${ }^{c}$ Weekly 50.000 Ui vs biweekly $100.000 \mathrm{Ui}$.

In addition, the $250 \mathrm{H}$ levels of the daily regimen group at week 8 were higher than both the ones of the weekly and the biweekly regimen groups both at week 8 and week 12 ( $p<0.000$ vs both groups).

No serious adverse event occurred.

Conclusion: All the three different regimens proved to be effective in correcting vitamin $D$ deficiency already after 1 months (2 weeks for the daily regimen). $A$ more refracted approach seems to more effective than the bolus-based regimens. The safety profile was excellent in all groups. 